\title{
Levothyroxine dose adjustment in hypothyroid women achieving pregnancy through IVF
}

\author{
Andrea Busnelli ${ }^{1,2}$, Guia Vannucchi ${ }^{1}$, Alessio Paffoni ${ }^{1}$, Sonia Faulisi ${ }^{1,2}$, \\ Laura Fugazzola $^{1,2}$, Luigi Fedele ${ }^{1,2}$ and Edgardo Somigliana ${ }^{1}$ \\ ${ }^{1}$ Infertility Unit, Fondazione Ca' Granda, Ospedale Maggiore Policlinico, Via M. Fanti, 6, 20122 Milan, \\ Italy and ${ }^{2}$ Università degli Studi, Milan, Italy
}

Correspondence should be addressed to A Busnelli

Email

andreabusnelli@live.it

\begin{abstract}
Objective: About one out of two women with primary hypothyroidism has to increase the dosage of exogenous levothyroxine ( $\left(-\mathrm{T}_{4}\right)$ during pregnancy. Considering the detrimental impact of IVF on thyroid function, it has been claimed but not demonstrated that $\mathrm{L}-\mathrm{T}_{4}$ dose adjustment may be more significant in hypothyroid women who become pregnant after IVF. Design: Retrospective cohort study.

Methods: Hypothyroid-treated women who achieved a live birth through IVF were reviewed. Women could be included if thyroid function was well compensated with $\mathrm{L}_{4} \mathrm{~T}_{4}$ before the IVF cycle (i.e., serum TSH $<2.5 \mathrm{mIU} / \mathrm{l}$ and serum free $\mathrm{T}_{4}$ within the normal range). Serum TSH and dose adjustment were evaluated at five time points during pregnancy. The trimester ranges for serum TSH considered as reference to adjust $\mathrm{L}_{4} \mathrm{~T}_{4}$ therapy were $0.1-2.5 \mathrm{mIU} / \mathrm{l}$ for the first trimester, $0.2-3.0 \mathrm{mIU} / \mathrm{l}$ for the second trimester, and $0.3-3.0 \mathrm{mlU} / \mathrm{l}$ for the third trimester.

Results: Thirty-eight women were selected. During the whole pregnancy 32 women (84\%; 95\% Cl: 72-96\%) required an increase in the dose of $\mathrm{L}_{4}$. In most cases $(n=28)$, this occured within the first $5-7$ weeks of gestation $(74 \%, 95 \% \mathrm{Cl}: 58-85 \%)$. At 5-7 weeks of gestation, the median (interquartile range) increase of $L-T_{4}$ dose for the whole cohort was $26 \%(0-50 \%)$. At 30-32 weeks, it was 33\% (14-68\%). In order to identify predictive factors of dose adjustment, we compared women who did $(n=28)$ and did not $(n=10)$ adjust $\mathrm{L}^{-\mathrm{T}_{4}}$ dosage at 5-7 weeks' gestation. Significant differences emerged for thyroid autoimmunity prevalence and for the distribution of hypothyroidism aetiology.

Conclusions: The vast majority of hypothyroid-treated women who achieve pregnancy through IVF need an increase in the $\mathrm{L}-\mathrm{T}_{4}$ dose during gestation. This requirement tends to occur very early during gestation.

\section{Introduction}

Pregnancy can be viewed as a prolonged physiological condition in which a combination of events modifies the thyroidal economy (1). During the first trimester, human chorionic gonadotropin (hCG) increases temporarily. This hormone possesses an intrinsic, albeit weak, thyroid stimulating activity (2). Simultaneously with this event and throughout the entire pregnancy, one can observe the estrogen-driven increase in the concentration of thyroxinebinding globulin (TBG), which results in a marked fall in serum-free thyroxine $\left(\mathrm{T}_{4}\right)$ concentrations and (c) 2015 European Society of Endocrinology Printed in Great Britain thyrotropin (TSH) increase. These two pivotal events, acting in opposite directions, maintain the homeostasis in euthyroid pregnant women. On the contrary, during gestation in women with primary hypothyroidism, the thyroid is not able to adjust the secretion of $\mathrm{T}_{4}$ to adequately compensate for the increased availability of binding sites and request (3). Therefore, an increased dosage of replacement levothyroxine $\left(\mathrm{L}-\mathrm{T}_{4}\right)$ is commonly necessary in these patients to maintain homeostasis (Table 1). Given the well-known significant adverse effects

Published by Bioscientifica Ltd 
Table 1 Studies on L-T 4 adjustment during natural pregnancy in hypothyroid-treated women. Only Alexander et al. reported separately data for ART pregnancies (and data was excluded form this table). This information is lacking for all the other contributions and we assumed that all of them were natural pregnancies.

\begin{tabular}{|c|c|c|c|c|}
\hline References & Study design & $\begin{array}{l}\text { No. of needing } \\
\text { increase/total }\end{array}$ & Percentage $(95 \% \mathrm{Cl})$ & Therapeutic goal \\
\hline (20) & Prospective & $8 / 37$ & $22 \%(11-37 \%)$ & $\mathrm{TSH}<7.0 \mathrm{mIU} / \mathrm{l}$ \\
\hline (31) & Retrospective & $9 / 12$ & $75 \%(57-91 \%)$ & $\mathrm{TSH}<5.0 \mathrm{mIU} / \mathrm{l}$ \\
\hline (32) & Retrospective & $35 / 77$ & $46 \%(35-57 \%)$ & $\mathrm{TSH}<4.0 \mathrm{mIU} / \mathrm{l}$ \\
\hline
\end{tabular}

Prospective

Prospective

Retrospective

Prospective

Retrospective

Retrospective
$44 \%(23-67 \%)$

$\mathrm{TSH} \leq 4.7 \mathrm{mIU} / \mathrm{l}$

$13 / 16$

$34 / 89$

$42 / 63$

$134 / 155$

$17 / 45^{b}$
$38 \%(25-52 \%)$

$\mathrm{TSH} \leq 4.1 \mathrm{mlU} / \mathrm{l}$

and $\leq 4.0 \mathrm{mlU} /$

(second and third trimesters)

$\mathrm{TSH}<2.5 \mathrm{mlU} / \mathrm{l}$

$87 \%(80-91 \%)$

The mean increase at the end of pregnacy was: $70 \pm 52 \%$ in patients with $\mathrm{SH} ; 45 \pm 27 \%$ in patients with $\mathrm{OH}$; and $49 \pm$ $24 \%$ in patients with $\mathrm{PH}$

The entire group required a mean cumulative increase from baseline of $13 \%$ in the first trimester, $26 \%$ in the second trimester, and $26 \%$ in the third trimester

The median increase was: in the first trimester $34 \%$ in patients with $\mathrm{SH}$ and $8 \%$ in patients with $\mathrm{OH}$; in the second trimester, it was $9 \%$ in patients with $\mathrm{SH}$ and $0 \%$ in patients with $\mathrm{OH}$

TSH, thyroid-stimulating hormone; $\mathrm{SH}$, subclinical hypothyroidism; $\mathrm{OH}$, overt hypothyroidism; $\mathrm{PH}$, post-ablative hypothyroidism. The proportion of women requiring $\mathrm{L}^{-\mathrm{T}_{4}}$ dose adjustment resulted highly hereterogeneous among studies $(P<0.001)$

${ }^{a}$ Refers to women whose optimal doses were known both before and during pregnancy.

${ }^{\mathrm{b}}$ Refers to first-trimester.

on pregnancy and fetal development of both subclinical and overt hypothyroidism (4), an appropriate $\mathrm{L}^{-\mathrm{T}_{4}}$ replacement scheme is mandatory. In a recent randomized clinical trial (RCT), Yassa et al. (5) conclude that a 30\% increase in $\mathrm{L}_{-} \mathrm{T}_{4}$ at confirmation of pregnancy significantly reduces the risk of maternal hypothyroidism during the first trimester and mimics normal physiology.

There is a growing body of evidence suggesting an impact of controlled ovarian hyperstimulation $(\mathrm{COH})$ on thyroid function. Several independent studies have 
reported a significant increase in serum TSH during $\mathrm{COH}$ or within 1 month after $\operatorname{COH}(6,7,8,9,10,11,12)$. The causes of these modifications have not yet been fully clarified. Different study groups have claimed a key role of estrogen increase. During IVF procedures, the marked rise in estradiol levels may induce a severe strain on the hypothalamic-pituitary-thyroid axis and alter the distribution and kinetics of thyroid hormones $(12,13)$. In particular, the increase in TSH may result from an estrogen-induced rise in TBG concentrations, as a consequence of an increased hepatic production associated with a reduced clearance rate. The magnitude of the TSH increase seems to be particularly pronounced among hypothyroid women. In a previous study, we observed that during $\mathrm{COH}$, serum TSH exceeded the recommend threshold of $2.5 \mathrm{mIU} / \mathrm{l}$ in up to two-thirds of adequately treated hypothyroid patients, and this increase tends to persist after the end of $\mathrm{COH}$ (14).

Considering such a considerable impairment of the thyroid function during $\mathrm{COH}$, one could speculate that hypothyroid women who become pregnant after IVF may require, especially in early gestation, a different $\mathrm{L}-\mathrm{T}_{4}$ dose adjustment. An elegant prospective study aimed at identifying precisely the timing and amount of $\mathrm{L}-\mathrm{T}_{4}$ adjustment required during pregnancy tends to support this hypothesis (15). The authors indeed observed that women who became pregnant by means of assisted reproductive techniques have an earlier and greater increase in serum levels of TSH than those who conceive naturally. However, this observation was based on only three cases, and more robust evidence is warranted. Given the clinical relevance of this topic, we deemed of interest reporting on $\mathrm{L}^{-} \mathrm{T}_{4}$ adjustments during gestation in a large series of hypothyroid women who become pregnant through IVF.

\section{Subjects and methods}

Women who achieved a live birth through IVF-ICSI cycles between January 2011 and December 2013 at the Infertility Unit of the Fondazione Ca' Granda Ospedale Maggiore Policlinico were reviewed. Women who were diagnosed with overt or subclinical hypothyroidism before the IVFICSI cycle and who were receiving $\mathrm{L}_{-} \mathrm{T}_{4}$ were considered for study entry. The different causes of hypothyroidism are reported in Table 2 . They were included in the study if thyroid function was strictly monitored and managed during pregnancy. More specifically, we included women who were evaluated in at least five precise time points during pregnancy: i) between the 5th and 7 th week of gestation, ii) between the 11th and 13th week of gestation, iii) between the 20th and the 22nd week of gestation, iv) between the 30th and the 32nd week of gestation, and v) between the 4 th and the 6 th week after delivery. Patients who developed ovarian hyperstimulation syndrome $(n=3)$ were not included in the study. The study was approved by the local Institutional Review Board.

Data were collected using the patients' chart of the Infertility, Obstetrical and Endocrinological Units of the Fondazione $\mathrm{Ca}^{\prime}$ Granda Ospedale Maggiore Policlinico. Phone follow-ups were performed for missing data or if available information was inconsistent. If required, women were requested to send the missing data by mail or fax. Women who sent incomplete information $(n=5)$ were excluded.

The precise protocol used for IVF in our clinic is reported in detail elsewhere (16). Of interest here is that

Table 2 Baseline and IVF cycle characteristics of the 38 selected women.

\begin{tabular}{|c|c|}
\hline Characteristics & Mean \pm s.D. or $n(\%)$ \\
\hline Age (years) & $35.2 \pm 3.9$ \\
\hline BMI $\left(\mathrm{kg} / \mathrm{m}^{2}\right)$ & $22.5 \pm 3.7$ \\
\hline Serum AMH (ng/ml) & $2.9 \pm 2.8$ \\
\hline Day 3 serum FSH (IU/ml) & $7.3 \pm 2.0$ \\
\hline Basal serum TSH (mIU/l) & $1.6 \pm 0.6$ \\
\hline $\mathrm{FT}_{4}(\mathrm{pg} / \mathrm{ml})$ & $11.3 \pm 3.2$ \\
\hline Positive thyroid autoimmunity & $27(71 \%)$ \\
\hline \multicolumn{2}{|l|}{ Hypothyroidism etiology } \\
\hline Hashimoto's thyroiditis & $24(63 \%)$ \\
\hline Treatment for Graves' disease ${ }^{a}$ & $2(5 \%)$ \\
\hline Treatment for thyroid cancer & $3(8 \%)$ \\
\hline TAI negative hypothyroidism & $9(24 \%)$ \\
\hline Levothyroxine dose ( $\mu \mathrm{g} / \mathrm{day})$ & $64 \pm 28$ \\
\hline \multicolumn{2}{|l|}{ Indication to IVF-ICSI } \\
\hline Male factor & $15(39 \%)$ \\
\hline Tubal factor & $2(5 \%)$ \\
\hline Endometriosis & $7(18 \%)$ \\
\hline $\begin{array}{l}\text { Unexplained/reduced ovarian } \\
\text { reserve }\end{array}$ & $9(24 \%)$ \\
\hline Mixed & $5(13 \%)$ \\
\hline \multicolumn{2}{|l|}{ Protocol of stimulation } \\
\hline Long protocol & $19(50 \%)$ \\
\hline GnRH antagonists & $14(37 \%)$ \\
\hline Short protocol & $5(13 \%)$ \\
\hline Duration of stimulation (days) & $9.8 \pm 2.1$ \\
\hline Total amount of rFSH administered & $5250 \pm 2407$ \\
\hline $\begin{array}{l}\text { Serum estradiol at hCG adminis- } \\
\text { tration }(\mathrm{pg} / \mathrm{ml})\end{array}$ & $1871 \pm 1051$ \\
\hline Total number of oocytes retrieved & $8.4 \pm 3.1$ \\
\hline Total number of oocytes used & $5.5 \pm 2.1$ \\
\hline Total number of embryos obtained & $3.2 \pm 1.4$ \\
\hline Number of embryos transferred & $1.8 \pm 0.5$ \\
\hline
\end{tabular}

$\mathrm{AMH}$, anti-Müllerian hormone; FSH, follicle-stimulating hormone; $\mathrm{TSH}_{\text {, }}$ thyroid-stimulating hormone; $\mathrm{FT}_{4}$, free thyroxine; $\mathrm{TAl}$, thyroid autoimmunity; GnRH, gonadotropin-releasing hormone; hCG, human chorionic gonadotropin.

${ }^{\mathrm{a}}$ Both cases underwent radioactive iodine ablation. 
serum TSH was systematically tested prior to initiating the IVF cycle. Only women with optimal serum TSH (between 0.1 and $2.5 \mathrm{mIU} / \mathrm{l}$ ) could start the cycle. Women who had levels $>2.5 \mathrm{mIU} / \mathrm{l}$ were referred to the endocrinologists for $\mathrm{L}-\mathrm{T}_{4}$ adjustment or initiation. Women were actually never censored because of abnormal levels. In these cases, the cycle was only delayed until optimal levels were reached. During the IVF cycle, serum TSH was not assessed and the $\mathrm{L}-\mathrm{T}_{4}$ dose was not adjusted.

The trimester-specific ranges considered as reference to adjust $\mathrm{L}-\mathrm{T}_{4}$ therapy were those suggested by the two major scientific associations on the subject: first trimester, 0.1-2.5 mIU/1; second trimester, $0.2-3.0 \mathrm{mIU} / \mathrm{l}$; and third trimester, $0.3-3.0 \mathrm{mIU} / \mathrm{l}(17,18)$. Pregnant women with hypothyroidism were tested monthly for serum $\mathrm{TSH}$, and if serum TSH was not within these thresholds, $\mathrm{L}_{-} \mathrm{T}_{4}$ was adjusted.

Serum TSH was tested using the Immulite analyser, a fully automated solid-phase third-generation immunoassay analyser with a chemiluminescent detection system (Diagnostic Products Corp., Los Angeles, CA, USA). The intra- and inter-assay coefficients of variation around the values of normal range were both $<10 \%$. TPO and TG antibodies were measured using commercial diagnostic kits involving an immunofluorescence assay (Phadia; Thermo Scientific, Waltham, MA, USA), with normal values set at $<35$ IU/1 (anti-TPO) and < 40 IU/1 (anti-TG).

Data analysis was performed using the Statistics Package for Social Sciences (SPSS 18.0). Data were compared using ANOVA for repeated measures, Student's $t$-test, Wilcoxon's test for unpaired data, or Fisher's exact test, as appropriate. A binomial distribution model was used to calculate the $95 \%$ CI of proportions. We deem clinically relevant demonstrating that the proportion of women needing dose adjustment would increase from $56 \%$ in natural pregnancy (Table 1) to more than $80 \%$ in IVF pregnancies. Setting type 1 and 2 errors to 0.05 and 0.20 , respectively, we calculated that we needed at least 30 women.

\section{Results}

Thirty-eight women were ultimately selected. Baseline and IVF cycle characteristics of these women are shown in Table 2 . The daily dose of $\mathrm{L}^{-} \mathrm{T}_{4}$ assumed before pregnancy was $64 \pm 28 \mu \mathrm{g}$. The modification of the dose during pregnancy is illustrated in Fig. 1. During the whole pregnancy, 32 women (84\%; 95\% CI: 72-96\%) required an increase in the dose of $\mathrm{L}^{-} \mathrm{T}_{4}$ (Table 3$)$. In most cases $(n=28)$, this occured within the first 5-7 weeks of gestation (74\%, 95\% CI: 58-85\%). Subsequently, only a minority of women $(n=4)$ required adjustment. At 5-7 weeks' gestation, the

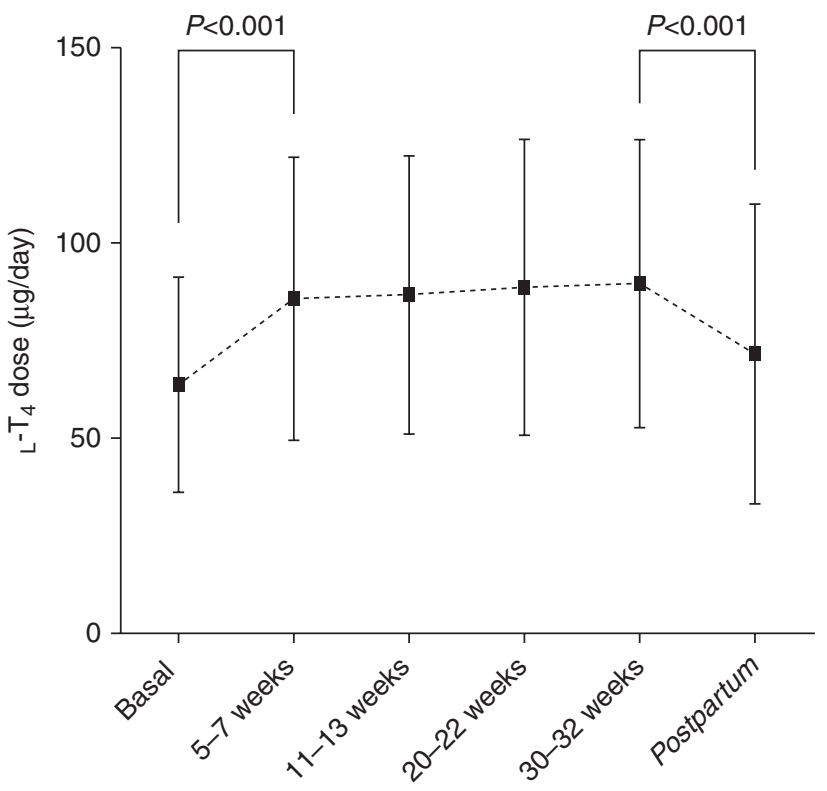

\section{Figure 1}

Daily dose of $L-\mathrm{T}_{4}$ during pregnancy. The mean \pm s.D. daily dose of $\mathrm{L}^{-\mathrm{T}_{4}}$ is reported. A statistically significant increase occurs between baseline and 5-7 weeks' gestation. Thereafter, the dose continued to increase during pregnancy but not in a statistically significant manner. After delivery, a statistically significant drop occurs.

median increase of $\mathrm{L}^{-\mathrm{T}_{4}}$ dose was $26 \%$ (interquartile range (IQR): 0-50\%). It was 33\% (IQR: 26-63\%) when exclusively focusing on women who did adjust the dose. Subsequently, only a milder increase was observed. The maximum dose of $\mathrm{L}-\mathrm{T}_{4}$ was reached at 30-32 weeks when the median increase from baseline for the whole cohort and for women who did adjust the dose was 33\% (IQR: 14-68\%) and 50\% (IQR: 25-75\%) respectively. After delivery, $\mathrm{L}-\mathrm{T}_{4}$ requirements dropped significantly. Only 17 women $(45 \%, 95 \% \mathrm{CI}$ : $30-60 \%$ ) were assuming higher dosages of $\mathrm{L}-\mathrm{T}_{4}$ (Table 3 ).

In order to identify predictive factors of early dose adjustment, we compared women who did $(n=28)$ and did not $(n=10)$ adjust $\mathrm{L}-\mathrm{T}_{4}$ dosage at 5-7 weeks' gestation. Results are shown in Table 4. Significant differences emerged for thyroid autoimmunity prevalence and for the distribution of hypothyroidism. Serum estrogens at the time of hCG was also higher in women requiring adjustment but the difference did not reach frank statistical significance $(P=0.06)$.

\section{Discussion}

During the whole gestation, $84 \%$ of women achieving pregnancy through IVF needed an increase in the dose of 
Table 3 TSH and L-T 4 modifications during pregnancy and postpartum.

\begin{tabular}{l} 
Time period \\
\hline Before pregnancy \\
$5-7$ weeks of gestation \\
$11-13$ weeks of gestation \\
$20-22$ weeks of gestation \\
$30-32$ weeks of gestation \\
$4-6$ weeks after delivery
\end{tabular}

\begin{tabular}{c}
\hline TSH $(\mathrm{mIU} / \mathrm{l})$ \\
\hline $1.6 \pm 0.6$ \\
$4.8 \pm 6.0$ \\
$2.2 \pm 0.7$ \\
$2.1 \pm 0.8$ \\
$2.1 \pm 0.8$ \\
$2.0 \pm 0.7$
\end{tabular}

\begin{tabular}{l}
\hline L-T $\mathbf{4}$ ( $\mathrm{g} / \mathrm{day})$ \\
\hline $63.7 \pm 27.5$ \\
$85.7 \pm 36.2$ \\
$86.7 \pm 35.7$ \\
$88.7 \pm 37.9$ \\
$89.6 \pm 36.9$ \\
$71.6 \pm 38.5$ \\
\hline
\end{tabular}

\begin{tabular}{|c|c|}
\hline \multicolumn{2}{|c|}{ Women increasing $L-\mathrm{T}_{4}{ }^{a}$} \\
\hline$n(\%)$ & $95 \% \mathrm{Cl}$ \\
\hline Ref & \\
\hline $28(74 \%)$ & $58-85 \%$ \\
\hline $30(79 \%)$ & $64-89 \%$ \\
\hline $32(84 \%)$ & $70-93 \%$ \\
\hline $32(84 \%)$ & $70-93 \%$ \\
\hline $17(45 \%)$ & $30-60 \%$ \\
\hline
\end{tabular}

\begin{tabular}{|c|c|}
\hline \multicolumn{2}{|c|}{ Rate of increase $^{a}$} \\
\hline Median (\%) & IQR (\%) \\
\hline Ref & \\
\hline 26 & $0-50$ \\
\hline 29 & $8-50$ \\
\hline 33 & $14-53$ \\
\hline 33 & $14-68$ \\
\hline 0 & 0-19 \\
\hline
\end{tabular}

\begin{tabular}{crr}
\hline \multicolumn{2}{c}{ Rate of increase $^{\text {b }}$} \\
\cline { 1 - 1 } \cline { 1 - 1 } Median (\%) & & IQR (\%) \\
\cline { 1 - 1 } Ref & & \\
33 & & $25-63$ \\
33 & & $24-68$ \\
42 & & $25-69$ \\
50 & & $25-75$ \\
39 & & $25-63$ \\
\hline
\end{tabular}

TSH, thyroid-stimulating hormone; $\mathrm{L}_{4}$, levothyroxine.

${ }^{\text {a }}$ Refers to the whole cohort.

${ }^{\mathrm{b}}$ Refers only to women who actually increased $\mathrm{L}-\mathrm{T}_{4}$ dose.

$\mathrm{L}-\mathrm{T}_{4}$ to maintain euthyroidism. The highest increment was observed in early pregnancy. Three out of four women required dose adjustment within 5-7 weeks' gestation. Subsequently, the $\mathrm{L}^{-\mathrm{T}_{4}}$ dose requirement continued to rise gradually but in a less striking manner and reached the maximum at 30-32 weeks. Postpartum, the average dose of required $\mathrm{L}_{-} \mathrm{T}_{4}$ rapidly dropped.
Our study supports the idea that $\mathrm{L}^{-\mathrm{T}_{4}}$ adjustment is more relevant in hypothyroid women achieving pregnancy through IVF. Based on our meta-analysis of the available studies reporting on $\mathrm{L}^{-\mathrm{T}_{4}}$ adjustment in pregnancy (Table 1), the proportion of women requiring adjustment resulted 56\% (95\% CI: 52-60\%), which is considerably lower than the 84\% (95\% CI: 70-93\%)

Table 4 Baseline characteristics of women who did and did not require an increase in $L-\mathrm{T}_{4}$ dose at the first endocrinological consultation (performed at 5-7 weeks of pregnancy). Data are reported as $n$ (\%) or mean \pm s.D., as appropriate.

\begin{tabular}{|c|c|c|c|}
\hline & No. of L-T $\mathbf{T}_{4}$ increase $(n=10)$ & $\mathbf{L}-\mathbf{T}_{\mathbf{4}}$ increase $(n=28)$ & $P$ value \\
\hline Age (years) & $35.4 \pm 4.3$ & $35.1 \pm 4.0$ & 0.83 \\
\hline BMI $\left(\mathrm{kg} / \mathrm{m}^{2}\right)$ & $22.4 \pm 3.0$ & $22.5 \pm 4.0$ & 0.97 \\
\hline Serum AMH $(\mathrm{ng} / \mathrm{ml})$ & $2.9 \pm 2.4$ & $3.1 \pm 2.9$ & 0.50 \\
\hline Day 3 serum FSH (IU/ml) & $7.8 \pm 3.0$ & $7.1 \pm 1.7$ & 0.47 \\
\hline Basal serum TSH (mIU/l) & $1.5 \pm 0.6$ & $1.6 \pm 0.6$ & 0.86 \\
\hline $\mathrm{FT}_{4}(\mathrm{pg} / \mathrm{ml})$ & $11.8 \pm 2.4$ & $11.2 \pm 3.4$ & 0.69 \\
\hline Positive thyroid autoimmunity & $4(40 \%)$ & $23(82 \%)$ & 0.019 \\
\hline Hypothyroidism etiology & & & 0.04 \\
\hline Hashimoto's thyroiditis & $3(30 \%)$ & $21(75 \%)$ & \\
\hline Treatment for Graves' disease & $1(10 \%)$ & $1(4 \%)$ & \\
\hline Treatment for thyroid cancer & $1(10 \%)$ & $2(7 \%)$ & \\
\hline TAI negative hypothyroidism & $5(50 \%)$ & $4(14 \%)$ & \\
\hline Levothyroxine dose ( $\mu \mathrm{g} / \mathrm{day})$ & $60 \pm 37$ & $65 \pm 24$ & 0.70 \\
\hline Indication to IVF-ICSI & & & 0.57 \\
\hline Male factor & $4(40 \%)$ & $11(39 \%)$ & \\
\hline Tubal factor & $0(0 \%)$ & $2(7 \%)$ & \\
\hline Endometriosis & $3(30 \%)$ & $4(14 \%)$ & \\
\hline Unexplained/reduced ovarian reserve & $1(10 \%)$ & $8(29 \%)$ & \\
\hline Mixed & $2(20 \%)$ & $3(11 \%)$ & \\
\hline Protocol of stimulation & & & 0.20 \\
\hline Long protocol & $4(40 \%)$ & $15(54 \%)$ & \\
\hline GnRH antagonists & $3(30 \%)$ & $11(39 \%)$ & \\
\hline Short protocol & $3(30 \%)$ & $2(7 \%)$ & \\
\hline Duration of stimulation (days) & $9.0 \pm 2.4$ & $10.0 \pm 2.1$ & 0.30 \\
\hline Total amount of rFSH administered & $2713 \pm 1256$ & $2327 \pm 1212$ & 0.50 \\
\hline Serum estradiol at hCG administration ( $\mathrm{pg} / \mathrm{ml})$ & $1076 \pm 430$ & $2052 \pm 1071$ & 0.06 \\
\hline Total number of oocytes retrieved & $7.6 \pm 3.7$ & $8.6 \pm 3.1$ & 0.53 \\
\hline Total number of embryos obtained & $2.8 \pm 1.9$ & $3.3 \pm 1.3$ & 0.48 \\
\hline Number of embryos transferred & $1.8 \pm 0.4$ & $1.8 \pm 0.6$ & 0.48 \\
\hline
\end{tabular}

$\mathrm{AMH}$, anti-Müllerian hormone; FSH, follicle-stimulating hormone; TSH, thyroid-stimulating hormone; $\mathrm{FT}_{4}$, free thyroxine; TAl, thyroid autoimmunity; $\mathrm{GnRH}$, gonadotropin-releasing hormone; hCG, human chorionic gonadotropin. 
observed in our series. Noteworthy, the two $95 \%$ CIs do not overlap and the reported rates exceeded our $84 \%$ in only one of the ten identified studies (19). To note, this latter study refers to the most stringent criteria used for $\mathrm{L}^{-\mathrm{T}_{4}}$ adjustment (serum TSH had to maintain below $2.5 \mathrm{mIU} / 1$ for the whole duration of pregnancy). On the other hand, it is noteworthy that the results from previous contributions are highly heterogeneous. The proportion varies from $22 \%$ (20) to $87 \%$ (19). These relevant differences presumably reflect differences in study design (prospective vs retrospective), characteristics of the studied populations, and clinical criteria used to adjust $\mathrm{L}-\mathrm{T}_{4}$. Retrospective studies may underestimate the proportion of women requiring adjustment and the magnitude of the increase because physicians may be less rigorous in the use of the locally recommended thresholds. Verga et al. observed that the etiology of hypothyroidism influences the adjustment of L- $\mathrm{T}_{4}$ therapy. Women with subclinical hypothyroidism actually need a larger increase when compared to those with overt autoimmune hypothyroidism or post-ablative hypothyroidism (19). Abalovich et al. (21) also observed a higher need in women with subclinical hypothyroidism. In the present study, the positivity of anti-thyroid autoantibodies and, consistently, the autoimmune origin of hypothyroidism resulted statistically significantly associated with the need for $\mathrm{L}_{-} \mathrm{T}_{4}$ adjustment in early pregnancy, indicating that the contribution of the thyroid gland to the maintenance of euthyroidism is further impaired and becomes insufficient during pregnancy. This significant association and the high prevalence (50\%) of TAI-negative hypothyroidism in the group of patients who did not need to adjust $\mathrm{L}-\mathrm{T}_{4}$ dosage in early pregnancy indirectly support the thesis of a milder clinical course of TAI-negative hypothyroidism when compared with autoimmune hypothyroidism (22). Finally, it has to be emphasized that only one of the ten studies shown in Table 1 reported data separately for assisted reproductive technology (ART) pregnancies (15), and we cannot exclude that data from other contributions may have been inflated by the inclusion of some IVF pregnancies. The impact of the criteria used to adjust $\mathrm{L}_{\mathrm{L}} \mathrm{T}_{4}$ is obvious and intuitively relevant. As shown in Table 1, these criteria unfortunately varied substantially among the available evidence. In this regard, it is worth noting that only Abalovich et al. (21) referred to the same criteria used in our study. Interestingly, these authors reported a $32 \%$ rate of adjustment, markedly lower than the $84 \%$ observed in our series.

Our study also suggests that the pattern of $\mathrm{L}-\mathrm{T}_{4}$ modification during pregnancy differed in IVF pregnancies compared to natural pregnancies. Most of the increase in $\mathrm{L}-\mathrm{T}_{4}$ requirements actually occurred very early, within the first few weeks of pregnancy. In natural pregnancies, the increase in $\mathrm{L}^{-} \mathrm{T}_{4}$ is more gradual (15). This different pattern was already pointed out by Alexander et al. (15) in their small subgroup $(n=3)$ of women who became pregnant by means of assisted reproduction techniques. Estrogens might have a key role. In fact, in a recent study, Lv et al. (23) observed, during the first trimester, a higher level of estrogens in pregnancies achieved through IVF than in natural pregnancies. Noteworthy, there is consistent evidence showing a TSH rise during IVF in euthyroid women, and this increase appears to be more evident in women with treated hypothyroidism $(10,14)$. This modification mainly occurs during gonadotropin treatment (i.e., prior to hCG administration). In our series, we also observed a trend for higher serum estrogens at the time of hCG administration in women requiring early adjustment of $\mathrm{L}-\mathrm{T}_{4}$. On the other hand, data from studies in women undergoing IVF failed to show a pivotal role of estrogens in IVF-related serum TSH modifications $(10,11,14)$. Overall, even if estrogens may play a role, it is likely that other, yet obscure mechanisms are also involved.

We did not detect significant differences in the baseline TSH concentration in patients who did and did not require an increment in $\mathrm{L}-\mathrm{T}_{4}$ dosage during pregnancy. This is in contrast with previous studies on natural pregnancies. Both Abalovich et al. (21) and Kothari \& Girling (24) observed that, before pregnancy, the mean TSH value was lower in women who did not need additional $\mathrm{L}_{-} \mathrm{T}_{4}$ during pregnancy than in those who needed an increase. Abalovich et al. (21) also observed that only $17 \%$ of women with a preconception TSH lower than $1.2 \mathrm{mIU} / \mathrm{l}$ had to increase the $\mathrm{L}_{-} \mathrm{T}_{4}$ dose during pregnancy (21). Inconsistency with our findings may be explained by a type 2 error. Alternatively, the detrimental and yet unpredictable and unexplained effects of IVF may have diluted this effect.

Our study has some limitations. The most obvious is the absence of a control group. Further evidence comparing women who naturally achieved pregnancy and those becoming pregnant through IVF is warranted. This study design is not simple, however, because infertile women represent a peculiar group of women, and identifying a proper group of controls is complex. A prospective study is more suitable to prevent differences in clinical management, and a matched analysis may be more appropriate to prevent confounders. Women should indeed be matched at least for the cause of hypothyroidism and the baseline dosage of $\mathrm{L}-\mathrm{T}_{4}$. A second limitation is our retrospective study design. However, we do not deem this point of utmost relevance because great attention is 
given to thyroid dysfunctions in all the involved units of our institution. Moreover, a stringent and standardized policy for $\mathrm{L}-\mathrm{T}_{4}$ adjustment was used. Thirdly, we did not monitor the thyroid function during the IVF cycle. This could be an added value of future studies, since a link between thyroid autoimmunity and thyroid function and IVF may be evident also in the early phase of $\mathrm{COH}$ (25).

Our results have clinical and therapeutic implications. Promptly adjusting $\mathrm{L}^{-\mathrm{T}_{4}}$ already in the 1 st weeks of pregnancy is of utmost importance. Suboptimal thyroid function is in fact associated with adverse pregnancy outcomes including an increased risk of miscarriage, premature birth, gestational hypertension, placental abruption, and postpartum haemorrhage $(26,27,28)$, as well as impaired neurological development in the offspring $(28,29,30)$. Based on results from a RCT, Yassa et al. (5) suggested that a per default $30 \%$ increase of $\mathrm{L}_{-} \mathrm{T}_{4}$ significantly reduces the risk of maternal hypothyroidism during the first trimester and mimics normal physiology. Our data seem to suggest that women who achieve pregnancy through IVF may need a higher increase in the dose of $\mathrm{L}_{\mathrm{L}} \mathrm{T}_{4}$ immediately upon confirmation of pregnancy. Prospective studies are warranted to identify the most suitable management strategy. In the meantime, one can adopt the two-tablets increase approach but also strictly monitor serum TSH.

In conclusion, a high proportion of treated hypothyroid women who achieve pregnancy through IVF need an early increase in the $\mathrm{L}_{\mathrm{L}} \mathrm{T}_{4}$ dose during gestation. Requirements seem to be higher and to occur earlier when compared to natural pregnancy. Reasons behind these modifications remain to be fully clarified. Moreover, prospective studies are needed to identify the best management strategy to prevent gestational hypothyroidism in affected women.

\section{Declaration of interest}

The authors declare that there is no conflict of interest that could be perceived as prejudicing the impartiality of the research reported.

\section{Funding}

This research did not receive any specific grant from any funding agency in the public, commercial or not-for-profit sector.

\section{References}

1 Glinoer D. The regulation of thyroid function in pregnancy: pathways of endocrine adaptation from physiology to pathology. Endocrine Reviews 199718 404-433. (doi:10.1210/edrv.18.3.0300)
2 Roelfsema F \& Veldhuis JD. Thyrotropin secretion patterns in health and disease. Endocrine Reviews 201334 619-657. (doi:10.1210/er.20121076)

3 Toft A. Increased levothyroxine requirements in pregnancy - why, when, and how much? New England Journal of Medicine $2004 \mathbf{3 5 1}$ 292-294. (doi:10.1056/NEJMe048110)

4 Reid SM, Middleton P, Cossich MC, Crowther CA \& Bain E. Interventions for clinical and subclinical hypothyroidism pre-pregnancy and during pregnancy. Cochrane Database of Systematic Reviews 20135 CD007752. (doi:10.1002/14651858.CD007752.pub3)

5 Yassa L, Marqusee E, Fawcett R \& Alexander EK. Thyroid hormone early adjustment in pregnancy (the THERAPY) trial. Journal of Clinical Endocrinology and Metabolism 201095 3234-3241. (doi:10.1210/jc. 2010-0013)

6 Muller AF, Verhoeff A, Mantel MJ, De Jong FH \& Berghout A. Decrease of free thyroxine levels after controlled ovarian hyperstimulation. Journal of Clinical Endocrinology and Metabolism 200085 545-548. (doi:10.1210/jcem.85.2.6373)

7 Poppe K, Glinoer D, Tournaye H, Schiettecatte J, Devroey P, van Steirteghem A, Haentjens P \& Velkeniers B. Impact of ovarian hyperstimulation on thyroid function in women with and without thyroid autoimmunity. Journal of Clinical Endocrinology and Metabolism 200489 3808-3812. (doi:10.1210/jc.2004-0105)

8 Poppe K, Glinoer D, Tournaye H, Schiettecatte J, Haentjens P \& Velkeniers B. Thyroid function after assisted reproductive technology in women free of thyroid disease. Fertility and Sterility 2005 83 1753-1757. (doi:10.1016/j.fertnstert.2004.12.036)

9 Reinblatt S, Herrero B, Correa JA, Shalom-Paz E, Ata B, Wiser A, Morris D $\&$ Holzer H. Thyroid stimulating hormone levels rise after assisted reproductive technology. Journal of Assisted Reproduction and Genetics 201330 1347-1352. (doi:10.1007/s10815-013-0081-3)

10 Gracia CR, Morse CB, Chan G, Schilling S, Prewitt M, Sammel MD \& Mandel SJ. Thyroid function during controlled ovarian hyperstimulation as part of in vitro fertilization. Fertility and Sterility $2012 \mathbf{9 7}$ 585-591. (doi:10.1016/j.fertnstert.2011.12.023)

11 Benaglia L, Busnelli A, Somigliana E, Leonardi M, Vannucchi G, De Leo S, Fugazzola L, Ragni G \& Fedele L. Incidence of elevation of serum thyroid-stimulating hormone during controlled ovarian hyperstimulation for in vitro fertilization. European Journal of Obstetrics, Gynecology, and Reproductive Biology 2014173 53-57. (doi:10.1016/j. ejogrb.2013.11.003)

12 Mintziori G, Goulis DG, Toulis KA, Venetis CA, Kolibianakis EM \& Tarlatzis BC. Thyroid function during ovarian stimulation: a systematic review. Fertility and Sterility 201196 780-785. (doi:10.1016/j.fertnstert. 2011.06.020)

13 Krassas GE, Poppe K \& Glinoer D. Thyroid function and human reproductive health. Endocrine Reviews 201031 702-755. (doi:10.1210/ er.2009-0041)

14 Busnelli A, Somigliana E, Benaglia L, Sarais V, Ragni G \& Fedele L. Thyroid axis dysregulation during in vitro fertilization in hypothyroid-treated patients. Thyroid 201424 1650-1655. (doi:10.1089/thy.2014.0088)

15 Alexander EK, Marqusee E, Lawrence J, Jarolim P, Fischer GA \& Larsen PR. Timing and magnitude of increases in levothyroxine requirements during pregnancy in women with hypothyroidism. New England Journal of Medicine 2004351 241-249. (doi:10.1056/ NEJMoa040079)

16 Busnelli A, Somigliana E, Benaglia L, Leonardi M, Ragni G \& Fedele L. In vitro fertilization outcomes in treated hypothyroidism. Thyroid 2013 23 1319-1325. (doi:10.1089/thy.2013.0044)

17 Stagnaro-Green A, Abalovich M, Alexander E, Azizi F, Mestman J, Negro R, Nixon A, Pearce EN, Soldin OP, Sullivan S et al. Guidelines of the American Thyroid Association for the diagnosis and management of thyroid disease during pregnancy and postpartum. Thyroid 201121 1081-1112. (doi:10.1089/thy.2011.0087)

18 De Groot L, Abalovich M, Alexander EK, Amino N, Barbour L, Cobin RH Eastman CJ, Lazarus JH, Luton D, Mandel SJ et al. Management of 
thyroid dysfunction during pregnancy and postpartum: an Endocrine Society clinical practice guideline. Journal of Clinical Endocrinology and Metabolism 201297 2543-2565. (doi:10.1210/jc.2011-2803)

19 Verga U, Bergamaschi S, Cortelazzi D, Ronzoni S, Marconi AM \& BeckPeccoz P. Adjustment of $\mathrm{L}_{-} \mathrm{T}_{4}$ substitutive therapy in pregnant women with subclinical, overt or post-ablative hypothyroidism. Clinical Endocrinology 2009 70 798-802. (doi:10.1111/j.1365-2265.2008.03398.x)

20 Pekonen F, Teramo K, Ikonen E, Osterlund K, Mäkinen T \& Lamberg BA. Women on thyroid hormone therapy: pregnancy course, fetal outcome, and amniotic fluid thyroid hormone level. Obstetrics and Gynecology 198463 635-638.

21 Abalovich M, Alcaraz G, Kleiman-Rubinsztein J, Pavlove MM, Cornelio C, Levalle $\mathrm{O} \&$ Gutierrez S. The relationship of preconception thyrotropin levels to requirements for increasing the levothyroxine dose during pregnancy in women with primary hypothyroidism. Thyroid 201020 1175-1178. (doi:10.1089/thy.2009.0457)

22 Rotondi M, de Martinis L, Coperchini F, Pignatti P, Pirali B, Ghilotti S, Fonte R, Magri F \& Chiovato L. Serum negative autoimmune thyroiditis displays a milder clinical picture compared with classic Hashimoto's thyroiditis. European Journal of Endocrinology 2014171 31-36. (doi:10.1530/EJE-14-0147)

23 Lv PP, Meng Y, Lv M, Feng C, Liu Y, LiJY, Yu DQ, Shen Y, Hu XL, Gao Q etal. Altered thyroid hormone profile in offspring after exposure to high estradiol environment during the first trimester of pregnancy: a cross-sectional study. BMC Medicine 201412 240. (doi:10.1186/s12916-014-0240-0)

24 Kothari A \& Girling J. Hypothyroidism in pregnancy: pre-pregnancy thyroid status influences gestational thyroxine requirements. BJOG: an International Journal of Obstetrics and Gynaecology $2008 \mathbf{1 1 5}$ 1704-1708. (doi:10.1111/j.1471-0528.2008.01901.x)

25 Magri F, Capelli V, Gaiti M, Brambilla E, Montesion L, Rotondi M, Spinillo A, Nappi RE \& Chiovato L. Impaired outcome of controlled ovarian hyperstimulation in women with thyroid autoimmune disease. Thyroid 201323 1312-1318. (doi:10.1089/thy.2013.0022)

26 Abalovich M, Gutierrez S, Alcaraz G, Maccallini G, Garcia A \& Levalle O. Overt and subclinical hypothyroidism complicating pregnancy. Thyroid 200212 63-68. (doi:10.1089/105072502753451986)
27 Korevaar TI, Schalekamp-Timmermans S, de Rijke YB, Visser WE, Visser W, de Muinck Keizer-Schrama SM, Hofman A, Ross HA, Hooijkaas $\mathrm{H}$, Tiemeier $\mathrm{H}$ et al. Hypothyroxinemia and TPO-antibody positivity are risk factors for premature delivery: the Generation $\mathrm{R}$ Study. Journal of Clinical Endocrinology and Metabolism 201398 4382-4390. (doi:10.1210/jc.2013-2855)

28 Taylor PN, Minassian C, Rehman A, Iqbal A, Draman MS, Hamilton W, Dunlop D, Robinson A, Vaidya B, Lazarus JH et al. TSH levels and risk of miscarriage in women on long-term levothyroxine: a communitybased study. Journal of Clinical Endocrinology and Metabolism 201499 3895-3902. (doi:10.1210/jc.2014-1954)

29 Ghassabian A, Bongers-Schokking JJ, Henrichs J, Jaddoe VW, Visser TJ, Visser W, de Muinck Keizer-Schrama SM, Hooijkaas H, Steegers EA, Hofman A et al. Maternal thyroid function during pregnancy and behavioral problems in the offspring: the Generation R Study. Pediatric Research 201169 454-459. (doi:10.1203/PDR. Ob013e3182125b0c)

30 Haddow JE, Palomaki GE \& Allan WC. Maternal thyroid deficiency during pregnancy and subsequent neuropsychological development of the child. New England Journal of Medicine 1999341 549-555. (doi:10.1056/NEJM199908193410801)

31 Mandel SJ, Larsen PR, Seely EW \& Brent GA. Increased need for thyroxine during pregnancy in women with primary hypothyroidism. New England Journal of Medicine 1990323 91-96.

32 Kaplan MM. Assessment of thyroid function during pregnancy. Thyroid 199921 57-61.

33 Chopra IJ \& Baber K. Treatment of primary hypothyroidism during pregnancy: is there an increase in thyroxine dose requirement in pregnancy? Metabolism 200352 122-128.

34 Hallengren B, Lantz M, Andreasson B \& Grennert L. Pregnant women on thyroxine substitution are often dysregulated in early pregnancy. Thyroid 200919 391-394.

35 Loh JA, Wartofsky L, Jonklaas J \& Burman KD. The magnitude of increased levothyroxine requirements in hypothyroid pregnant women depends upon the etiology of the hypothyroidism. Thyroid $200919269-275$.

Received 9 February 2015

Revised version received 7 June 2015

Accepted 2 July 2015 